\title{
Reduction in static friction by deposition of a homogeneous diamond-like carbon (DLC) coating on orthodontic brackets
}

\author{
Shun AKAIKE 1 , Tohru HAYAKAWA ${ }^{2}$, Daishiro KOBAYASHI ${ }^{3}$, Yuko AONO ${ }^{3}$, Atsushi HIRATA ${ }^{3}$, Masanori HIRATSUKA \\ and Yoshiki NAKAMURA ${ }^{1}$ \\ ${ }^{1}$ Department of Orthodontics, Tsurumi University School of Dental Medicine, 2-1-3 Tsurumi, Tsurumi-ku, Yokohama 230-8501, Japan \\ ${ }^{2}$ Department of Dental Engineering, Tsurumi University School of Dental Medicine, 2-1-3 Tsurumi, Tsurumi-ku, Yokohama 230-8501, Japan \\ ${ }^{3}$ Tokyo Institute of Technology, 2-12-1 Ookayama, Meguro-ku, Tokyo 152-8550, Japan \\ ${ }^{4}$ Nanotec Corporation, 572-61 Toyofuta, Kashiwa City, Chiba 277-0872, Japan \\ Corresponding author, Shun AKAIKE; E-mail: akaike-shun@tsurumi-u.ac.jp
}

In orthodontics, a reduction in static friction between the brackets and wire is important to enable easy tooth movement. The aim of this study was to examine the effects of a homogeneous diamond-like carbon (DLC) coating on the whole surfaces of slots in stainless steel orthodontic brackets on reducing the static friction between the brackets and the wire. The DLC coating was characterized using Raman spectroscopy, surface roughness and contact angle measurements, and SEM observations. Rectangular stainless steel and titanium-molybdenum alloy wires with two different sizes were employed, and the static friction between the brackets and wire was measured under dry and wet conditions. The DLC coating had a thickness of approximately $1.0 \mu \mathrm{m}$ and an amorphous structure was identified. The results indicated that the DLC coating always led to a reduction in static friction.

Keywords: Diamond-like carbon, Amorphous carbon, Orthodontic bracket, Static friction, Coating

\section{INTRODUCTION}

In orthodontics, an important factor influencing tooth movement is the static friction that is present between the brackets and the wire. Lower friction enhances tooth movement due to more efficient force transmission to the teeth, which can allow the treatment period to be shortened without undesirable anchorage loss or pain to the patient ${ }^{1-5)}$.

Orthodontic friction depends on the dynamic relationship among the wire, bracket and ligature in the oral environment. Rigid heavy wire is effective for controlling the axis of anterior teeth while closing the extraction space by sliding mechanics ${ }^{6}$. However, the use of such rigid heavy wire leads to the problem of increased friction between the wire and the brackets ${ }^{4,7-9)}$.

There have been many studies on the reduction of friction between brackets and wire ${ }^{2,4,10-17)}$. These mainly involved the use of self-ligating brackets or deceasing the contact area between the brackets and the wire $^{4,6,14,17)}$. Although these methods are effective at reducing the ligation force and thus the friction, control of tooth movement is more difficult due to the reduced contact between the brackets and the wire. Furthermore, when rigid heavy wire is used at high angulation, the friction between the brackets and the wire is comparable to that for conventional brackets ${ }^{2}$.

There have some studies on reducing the friction between brackets and wire using surface treatments such as ion implantation, poly(tetrafluoroethylene) coating, and polyethylene coating of the wires and/or brackets ${ }^{10-13)}$.

Color figures can be viewed in the online issue, which is available at J-STAGE.

Received Apr 23, 2015: Accepted Jul 13, 2015

doi:10.4012/dmj.2015-130 JOI JST.JSTAGE/dmj/2015-130
Diamond-like carbon (DLC) coatings have recently been applied in many industrial applications because they confer excellent properties such as extreme surface hardness, low friction coefficients, chemical inertness, high wear resistance, and good biocompatibility ${ }^{18-20)}$.

Muguruma et al. ${ }^{14,15)}$ deposited a DLC coating on stainless steel brackets and stainless steel and nickeltitanium wires using a plasma-based ion implantation/ deposition method, and successfully reduced the friction. However, these studies were performed only under dry conditions, which are markedly different from those found in the oral environment. Furthermore, the homogeneous deposition of the DLC coating was not achieved on the slot surface of the bracket using the plasma-based ion implantation/deposition method, because of complex shape of the bracket. Chemical vapor deposition technique would be a useful method for depositing films on to the materials with complex shape.

The aim of the present study was to deposit a homogeneous DLC coating on the whole surface of slots in a stainless steel orthodontic bracket using plasmaenhanced chemical vapor deposition (PECVD). The morphology of the deposited films was characterized, and the friction between the coated brackets and wire was measured under dry and wet conditions.

\section{MATERIALS AND METHODS}

\section{Materials}

Table 1 shows the specifications of the brackets and wires used in this study. A total of 800 conventional stainless steel brackets (Metal bracket, Densply Sankin, Tokyo, Japan) were used. In the present study, half 
Table 1 Bracket and wire materials evaluated

\begin{tabular}{|c|c|c|c|c|}
\hline Material & Product & Size (inches) & $\begin{array}{c}\text { Chemical composition } \\
\text { (weight\%) }\end{array}$ & Manufacturer \\
\hline \multicolumn{5}{|l|}{ Bracket } \\
\hline Stainless steel bracket & Metal bracket & $0.022 \times 0.028$ & $\begin{array}{c}\text { Cr: } 18-20 \%, \mathrm{Ni}: 8-10 \% \text {, } \\
\text { C, Mn,P,S,Si: less than 5\%, } \\
\text { Fe: residual }\end{array}$ & $\begin{array}{l}\text { DENSPLY SANKIN, } \\
\text { Tokyo, Japan }\end{array}$ \\
\hline \multicolumn{5}{|l|}{ Wire } \\
\hline Stainless steel wire & $\begin{array}{c}\text { Stainless steel } \\
\text { wire }\end{array}$ & $\begin{array}{c}0.019 \times 0.025 \text { or } \\
0.021 \times 0.025\end{array}$ & $\begin{array}{c}\text { Cr: } 17-19 \%, \mathrm{Ni}: 8-10 \% \text {, } \\
\text { C, Mn,P,S,Si: less than 5\%, } \\
\text { Fe: residual }\end{array}$ & Ormco, CA, USA \\
\hline Titanium-molybdenum wire & $\begin{array}{l}\text { CAN BETA III } \\
\text { Wire }\end{array}$ & $\begin{array}{c}0.019 \times 0.025 \text { or } \\
0.021 \times 0.025\end{array}$ & $\begin{array}{c}\text { Ti:70-80\%, Zi:5-10\%, } \\
\text { T:4-8\%, Mo:10-20\% }\end{array}$ & $\begin{array}{c}\text { ORTHO Organizers, } \\
\text { CA, USA }\end{array}$ \\
\hline
\end{tabular}

were left non-coated (non-coated bracket) and half were coated with DLC (DLC-coated bracket). They had a slot with dimensions of $0.022 \times 0.028$ inches $(0.56 \times 0.71$ $\mathrm{mm}$ ), a mesiodistal width of $2.9 \mathrm{~mm}$, and no built-in torque or tip. Stainless steel (SS) (Stainless steel wire, Ormco, CA, USA) and titanium-molybdenum alloy (Ti-Mo) (CNA BETA III Wire, Ortho Organizers, CA, USA) orthodontic wires with two different rectangular dimensions, $0.019 \times 0.025$ inches $(0.48 \times 0.64 \mathrm{~mm})$ and $0.021 \times 0.025$ inches $(0.53 \times 0.64 \mathrm{~mm})$, were used in this study. These four types of wire are referred to as $0.019 \times 0.025 \mathrm{SS}, 0.021 \times 0.025 \mathrm{SS}, 0.019 \times 0.025 \mathrm{Ti}-\mathrm{Mo}$, and $0.021 \times 0.025 \mathrm{Ti}-\mathrm{Mo}$, respectively. The brackets and wires were ultrasonically cleaned in ethanol and then dried with compressed air.

\section{DLC coating procedure}

The DLC films were deposited on the whole surface of the slots in the stainless steel brackets using PECVD (NPS-330, Nanotec, Chiba, Japan). The brackets were held in a custom-made jig during the coating process. The slot surface was first subjected to argon ion etching for $90 \mathrm{~min}$ in an ionization deposition reactor in order to remove the oxide film. An intermediate layer was then deposited by PECVD for 20 min using a hexamethyldisiloxane source. This was followed by DLC coating for $60 \mathrm{~min}$ using a benzene source. All processes were performed under a vacuum in the same equipment, with a maximum ambient temperature of $182^{\circ} \mathrm{C}$.

\section{Characterization of the DLC coatings}

1. Raman spectroscopy

The characteristics of the DLC coating were analyzed using a laser Raman spectrophotometer (NRS-1000, Jasco, Tokyo, Japan). Raman spectroscopy was performed under $532 \mathrm{~nm}$ excitation from an argon ion laser, focused by a $\times 20$ microscope objective. The spectra were collected with an acquisition time of $60 \mathrm{~s}$ in static mode with the grating centered at $1,200 \mathrm{~cm}^{-1}$ and an average of 3 counts.

\section{Surface roughness}

The arithmetic average surface roughness $\mathrm{Ra}$, and the root mean squared surface roughness $\mathrm{Rq}$ were measured using a confocal laser scanning microscope (OLS 3000, Olympus, Tokyo, Japan). The scanning distance was $256 \mu \mathrm{m}$ and the cutoff value was $87.4 \mu \mathrm{m}$. Five different profiles for each specimen were obtained.

\section{Surface wettability}

Due to difficulties encountered when attempting to measure the contact angle on the slot surface of the stainless steel bracket, a 12 -mm-diameter disk of the same stainless steel in the bracket was used to measure contact angles. The DLC coating was deposited under the same conditions as those used for the bracket. The contact angle between a $1.0-\mu \mathrm{L}$ drop of phosphate buffered saline (PBS, pH=7.4, NaCl: 138 mmol, KCl: 2.7 mmol, $\mathrm{Na}_{2} \mathrm{HPO}_{4}$ : $10 \mathrm{mmol}, \mathrm{KH}_{2} \mathrm{PO}_{4}: 1.76 \mathrm{mmol}$ ) solution and the disk was measured using an optical microscope. All measurements were performed five times duplicate.

\section{SEM observations}

To determine the bonding characteristics and the thickness of the DLC coating, DLC-coated brackets were embedded in epoxy resin (Epon812, Nisshin EM, Tokyo, Japan) and were then cut in a direction perpendicular to the surface of the slot with the diamond band saw of a micro cutting machine (BS-300CP, EXAKT Apparatebau, Norderstedt, Germany) so as to provide a cross section of the coated surface of the slot. The cut surface was polished using a series of silicon carbide (800\#-4000\#) and alumina abrasive papers (p.s.=0.03 $\mu \mathrm{m})$. The specimen surfaces were then sputter-coated with pure gold and the cut surface of the bracket slot was observed using scanning electron microscopy (SEM, JSM-5600LV, JEOL, Tokyo, Japan) at an accelerating voltage of $10 \mathrm{kV}$.

\section{Static friction test}

Each bracket was bonded accurately to the center of a stainless steel plate with unfilled adhesive resin 
(Superbond ORTHOMITE, Sun Medical, Shiga, Japan), using the bracket-mounting device shown in Figs. 1A and 1B. This device allowed accurate positioning of the bracket in the horizontal and vertical directions. The plate was then attached to the custom-made friction-testing device, as indicated by (d) in Fig. 1C, connected to a universal testing machine (Instron 5565, Instron Japan, Kanagawa, Japan). The friction-testing device was a modified version of previously reported devices $^{4,14,16)}$. The adjustment plate was positioned using a pin pushed through holes within it and the base plate (Fig. $1 \mathrm{C}(\mathrm{b}$ and $\mathrm{c})$ ). The angle between the bracket and wire was precisely adjusted in one-degree steps using the adjustment plate (Fig. $1 \mathrm{C}(\mathrm{b}))$.

The upper end of a 6 -cm-long orthodontic wire was connected to the load cell of the universal testing machine and the lower end of the wire was connected to a $150 \mathrm{~g}$ weight. The wire was then ligated to the bracket using an elastomeric ligature (module $\mathrm{O}$, Ormco). The same person placed all elastomeric ligatures immediately before each test in order to avoid a decay in the ligature force.

Each bracket-wire combination was tested at angulations of $0^{\circ}, 1^{\circ}, 3^{\circ}, 5^{\circ}$, and $10^{\circ}$. Each wire was drawn through the bracket at a cross-head speed of 20 $\mathrm{mm} / \mathrm{min}$ for a distance of $5 \mathrm{~mm}^{21)}$. The static friction between the bracket and wire was measured as the initial peak force required to initiate movement of the wire through the bracket. This peak force was defined as the static friction ${ }^{4,17)}$.

In the test performed under wet conditions, the bracket and wire were sprayed with a PBS solution immediately before measurements ${ }^{22}$. Measurements were carried out at room temperature for both dry and wet conditions. Each combination of bracket and wire, angulation and dry or wet conditions was measured ten times.

For each bracket, the slot surface was observed by SEM at an accelerating voltage of $10 \mathrm{kV}$ before and after the friction test.

\section{Statistical analysis}

Statistical analyses were performed using SPSS (version 16.0J for Windows, IBM Japan, Tokyo, Japan) software. The mean and standard deviation (S.D.) of the static friction were calculated, and the results for the coated and non-coated brackets were compared using a $t$-test $(p<0.05)$. The static friction under dry and wet conditions was also compared using a paired $t$-test $(p<0.05)$.

A multiple regression analysis was performed to determine the contribution of different factors to the static friction. The factors examined were (1) the DLC coating (reference: non-coated bracket), (2) the type of conditions (reference: wet), (3) the wire material (reference: SS), (4) the wire size (reference: $0.019 \times 0.025$ inches), and (5) the angulation (reference: $0^{\circ}$ ). The standardized partial regression coefficient $(\beta)$ was used to quantify the difference among the experiment variables and to indicate whether an increase or a decrease occurred relative to the reference case.

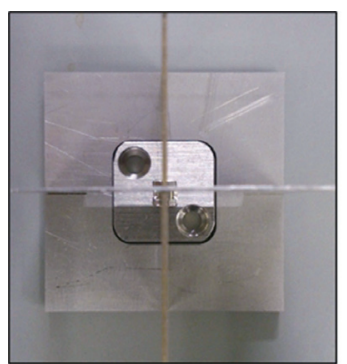

A

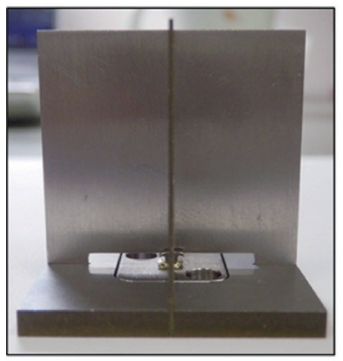

B

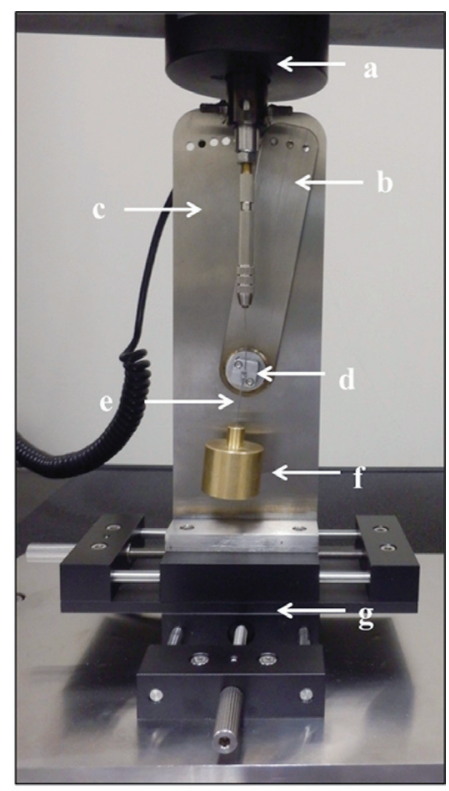

$\mathrm{C}$
Fig. 1 Custom-made friction-testing device.

A, B: Bracket-mounting device. C: Custom-made friction-testing device. (a) Load cell, (b) adjustment plate, (c) base plate, (d) bracket bonded stainless steel plate, (e) wire, (f) 150-g weight, and (g) x-y table.

Differences in the surface roughness and the contact angle between the PBS and the disk before and after coating with DLC were analyzed using a paired $t$-test. A $95 \%$ confidence interval was applied in all analyses, and differences were considered significant at $p<0.05$.

\section{RESULTS}

\section{Surface characterization}

1. Raman spectroscopy

The Raman spectrum of the DLC coating on the slot surface of the bracket exhibited a peak in the broad G-band derived from $s p^{2}$ carbon at approximately 1,540 $\mathrm{cm}^{-1}$ (Fig. 2). Additionally, a broad and weak D-band peak was observed at approximately $1,390 \mathrm{~cm}^{-1}$.

2. Measurement of surface roughness and contact angle The results of the surface roughness ( $\mathrm{Ra}, \mathrm{Rq})$ and contact angle measurements are listed in Table 2. No significant difference was observed in the slot surface roughness before or after coating with DLC $(p>0.05)$. However, there was a significant increase in the contact angle after coating with DLC $(p<0.05)$.

\section{SEM observation}

SEM revealed that the DLC coating was homogeneously deposited with a thickness of approximately $1.0 \mu \mathrm{m}$, and was strongly adhered to the entire slot surface (Fig. 3). 


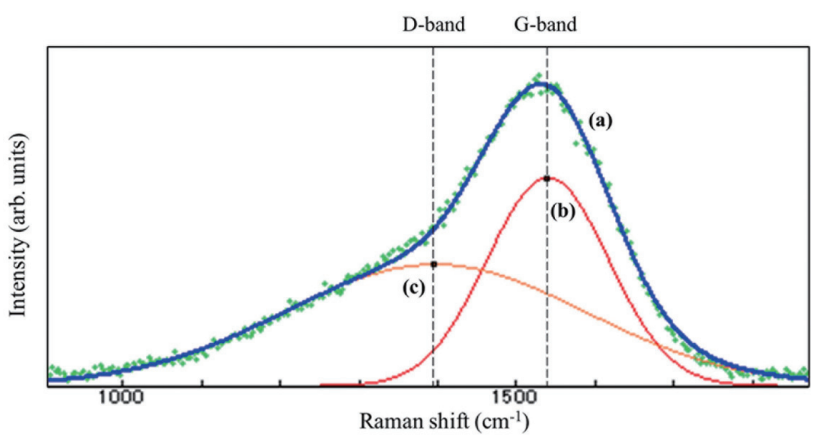

Fig. 2 Raman spectrum of DLC coating on surface of slot in bracket.

(a) DLC coating, (b) G-band, (c) D-band.

\section{Static friction test}

The static friction was found to be significantly lower for the DLC-coated brackets for all combinations of experimental factors: wire sizes, wire materials, angulations, and conditions (dry or wet) (Figs. 4 and 5). For both the coated and non-coated brackets, the static friction increased with increasing angulation and wire size. However, the increase was always smaller for the DLC-coated brackets. For both the coated and noncoated brackets, the static friction was lower for the SS wire than for the Ti-Mo wire.

A comparison of static friction between dry and wet conditions (Table 3) revealed a significant increase in static friction in non-coated brackets under a wet condition $(p<0.05)$, except for several combinations

Table 2 Surface roughness $\mathrm{Ra}$ and $\mathrm{Rq}$ (mean, S.D.) and contact angles against phosphate buffered saline (mean, S.D.) before and after DLC coating

\begin{tabular}{lccc}
\hline & Ra $(\mu \mathrm{m})$ & Rq $(\mu \mathrm{m})$ & \multicolumn{2}{c}{ Contact angle $\left({ }^{\circ}\right)$} \\
Mean $(\mathrm{S} . \mathrm{D})$. & Mean $(\mathrm{S} . \mathrm{D})$ & $1.029(0.463)$ & $37.88(4.74)$ \\
Non-coated bracket & $0.524(0.247)$ & $1.002(0.312)$ & $63.62(3.40)$ \\
DLC-coated bracket & $0.552(0.247)$ & n.s & $*$ \\
Significance & n.s. & & $*$ \\
\hline
\end{tabular}

${ }^{*} p<0.05$
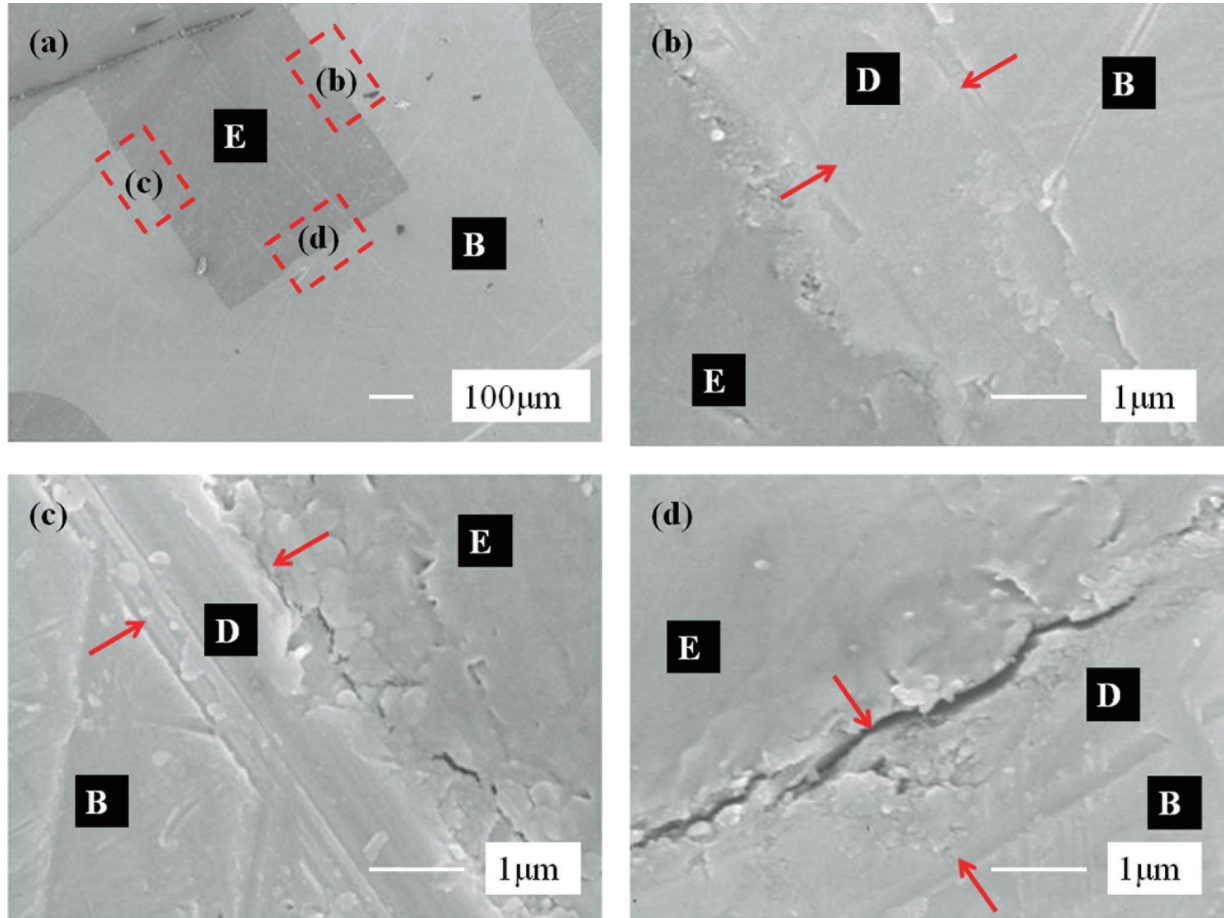

Fig. 3 Cross-sectional scanning electron microscopy images of DLC-coated bracket slot. The DLC layer (D) is present between the epoxy resin (E) and the bracket (B). (a) lowmagnification $(\times 70)$ image, (b) $-(\mathrm{d})$ high-magnification $(\times 18,000)$ images of the dashed rectangular regions in (a). 

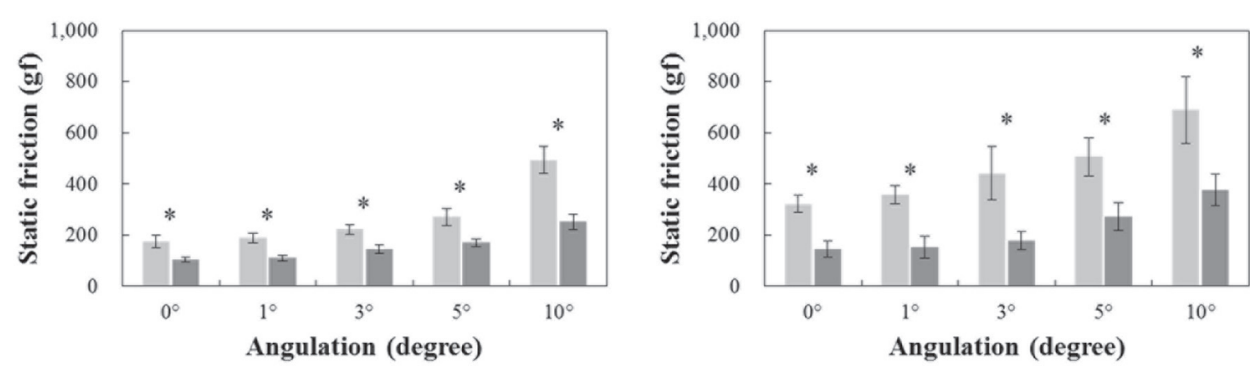

$0.019 \times 0.025 \mathrm{SS}$
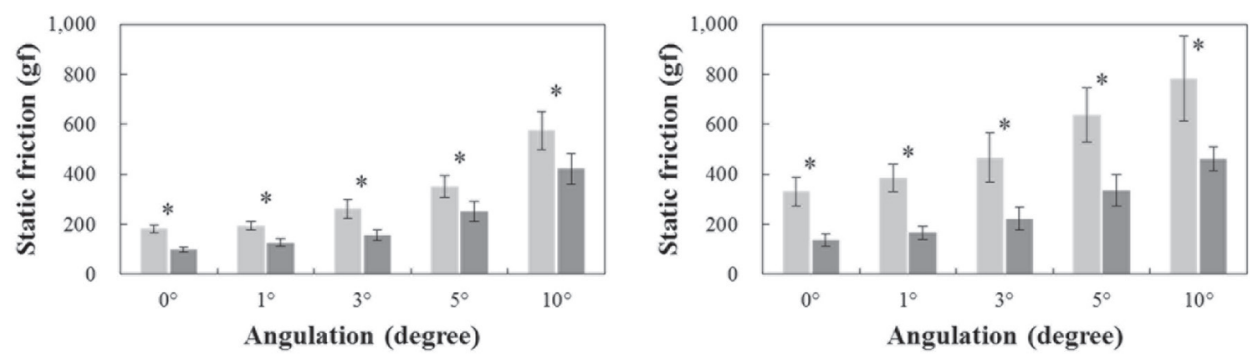

$0.021 \times 0.025 \mathrm{SS}$

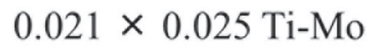

Non-coated bracket

= DLC-coated bracket

Fig. 4 Static friction under wet conditions for non-coated and DLC-coated brackets with different wires and angulation values.
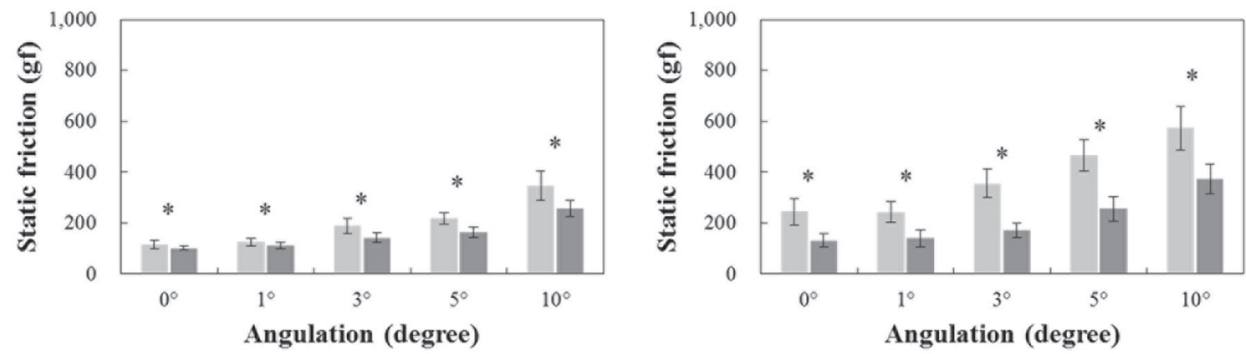

$0.019 \times 0.025 \mathrm{SS}$

$0.019 \times 0.025$ Ti-Mo
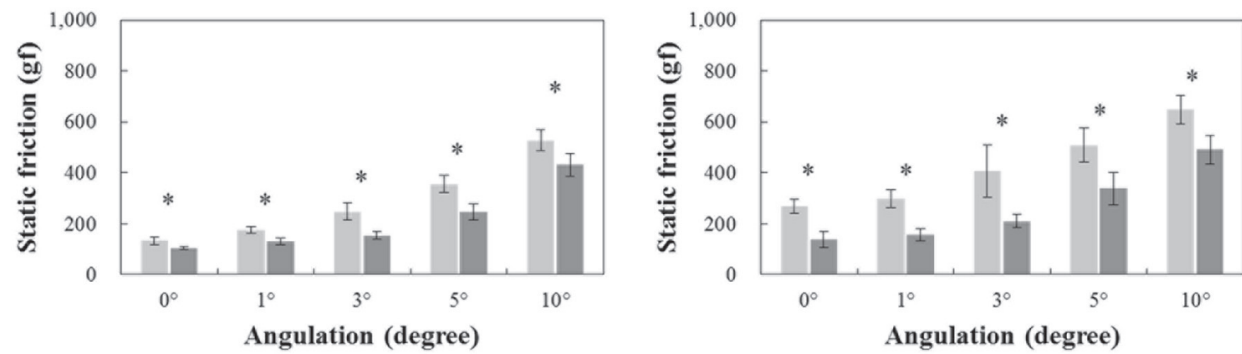

$0.021 \times 0.025 \mathrm{SS}$

$0.021 \times 0.025 \mathrm{Ti}-\mathrm{Mo}$

Non-coated bracket

= DLC-coated bracket

Fig. 5 Static friction under dry conditions for non-coated and DLC-coated brackets with different wires and angulation values. 
Table 3 Significant differences in static friction under dry and wet conditions

\begin{tabular}{|c|c|c|c|c|c|}
\hline \multirow[b]{2}{*}{ Non-coated bracket } & \multicolumn{5}{|c|}{ Angulation } \\
\hline & $0^{\circ}$ & $1^{\circ}$ & $3^{\circ}$ & $5^{\circ}$ & $10^{\circ}$ \\
\hline $0.019 \times 0.025 \mathrm{SS}$ & $*$ & $*$ & * & $*$ & $*$ \\
\hline $0.021 \times 0.025 \mathrm{SS}$ & $*$ & $*$ & - & - & - \\
\hline $0.019 \times 0.025 \mathrm{Ti}-\mathrm{Mo}$ & * & $*$ & * & - & $*$ \\
\hline $0.021 \times 0.025$ Ti-Mo & $*$ & $*$ & - & $*$ & $*$ \\
\hline DLC-coated bracket & $0^{\circ}$ & $1^{\circ}$ & $3^{\circ}$ & $5^{\circ}$ & $10^{\circ}$ \\
\hline $0.019 \times 0.025 \mathrm{SS}$ & - & - & - & - & - \\
\hline $0.021 \times 0.025 \mathrm{SS}$ & - & - & - & - & - \\
\hline $0.019 \times 0.025 \mathrm{Ti}-\mathrm{Mo}$ & - & - & - & - & - \\
\hline $0.021 \times 0.025 \mathrm{Ti}-\mathrm{Mo}$ & - & - & - & - & - \\
\hline
\end{tabular}

${ }^{*} p<0.05$

Table 4 Standardized partial regression coefficient $(\beta)$ and $p$ value for different factors obtained from multiple regression analysis of static friction

\begin{tabular}{lcc}
\hline \multicolumn{1}{c}{ Factor } & $\beta$ & $p$ \\
\hline DLC coating & -0.474 & $<0.05$ \\
Condition & -0.061 & $<0.05$ \\
Wire material & 0.311 & $<0.05$ \\
Wire size & 0.172 & $<0.05$ \\
Angulation & 0.662 & $<0.05$ \\
\hline
\end{tabular}

$\left(0.021 \times 0.025 \mathrm{SS}\right.$ wire at angulation of $3^{\circ}, 5^{\circ}$ and $10^{\circ}$, $0.019 \times 0.025 \mathrm{Ti}-\mathrm{Mo}$ wire at angulation of $5^{\circ}, 0.021 \times 0.025$ Ti-Mo wire at angulation of $3^{\circ}$ ).

The multiple regression analysis showed that all factors had a significant positive or negative effect on the static friction (Table 4). The most significant factor for reducing the static friction was the presence of the DLC coating $(\beta=-0.474)$, while the most significant factor for increasing the static friction was the angulation $(\beta=0.622)$.

The SEM images shown in Fig. 6 indicate that there was no difference in the slot surface morphology following DLC coating. There was also no difference following the static friction test, and no cracking or damage was observed.

\section{DISCUSSION}

The primary goal of the present study was to obtain a homogeneous DLC coating on the entire slot surface in the bracket. In a preliminary experiment, the DLC coating was deposited using an ionization deposition method. However, since this coating was found to contain defects, the PECVD method was employed in the present study, as it was expected to be superior for materials with complex shapes. The SEM results indicated that a homogeneous coating with a thickness of about $1 \mu \mathrm{m}$ was successfully produced using this method.

The presence of G- and D-band peaks in the Raman spectra of a coated bracket indicated that the DLC coating had an amorphous carbon structure ${ }^{23)}$. Ferrari et $a l .{ }^{24)}$ reported that the G-band peak position depends on the fraction of $s p^{2}$ bonds. The $s p^{2}$ fraction in the present DLC coating was estimated to be approximately $50 \%$ based on the peak separation. Furthermore, the DLC coating is considered to consist of hydrogenated amorphous carbon (a-C:H) because benzene was used as the carbon source.

The surface roughness of orthodontic wires and brackets has been shown to influence friction ${ }^{25-29)}$. However, in the present study, no marked change was observed in the roughness of the slot surface after the DLC coating, so that any detrimental effect on friction was negligible.

Downing et $a l{ }^{30}$ ) examined the influence of dry and wet conditions on friction between polycrystalline brackets and stainless steel, nickel-titanium, and betatitanium archwires. They demonstrated that the friction 

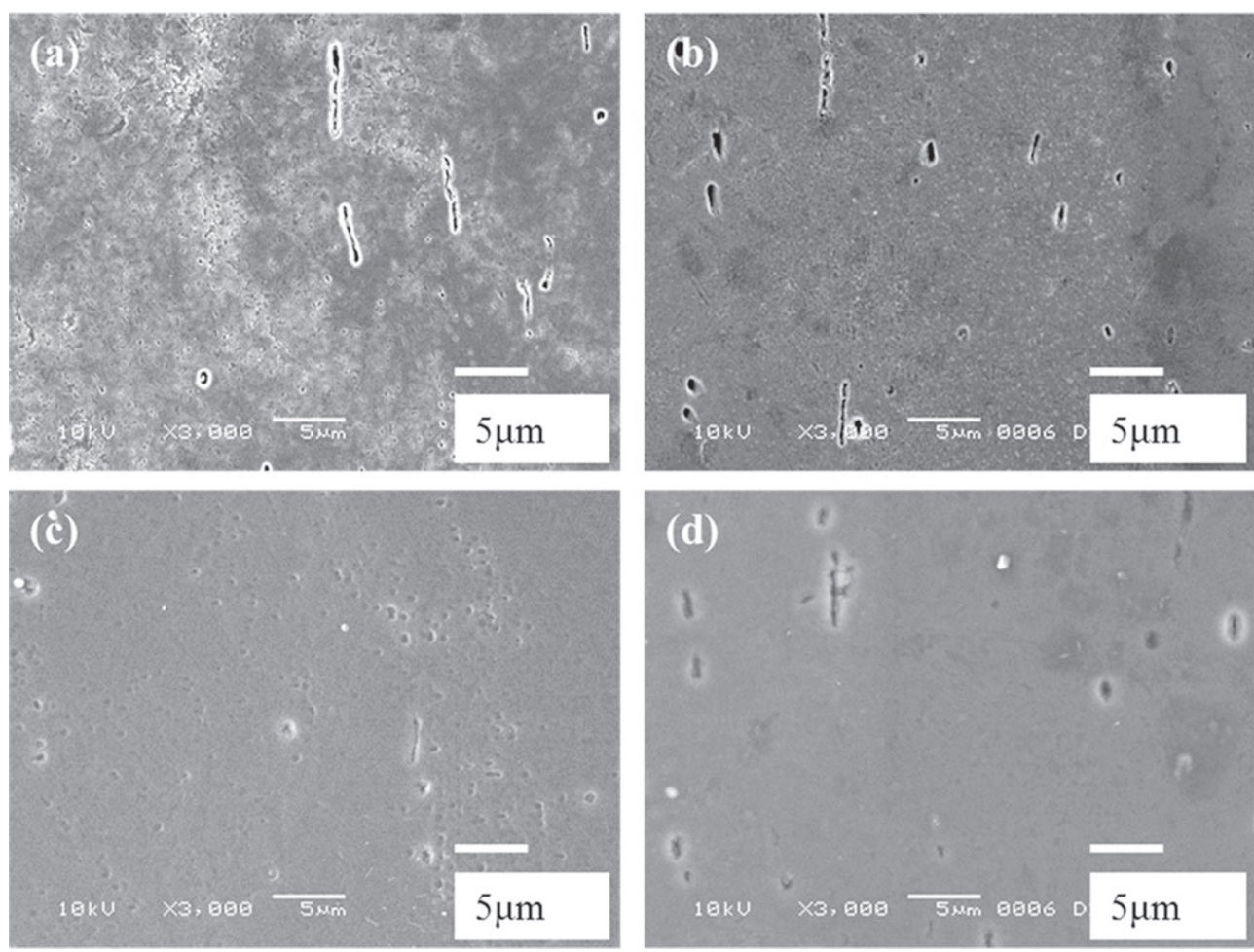

Fig. 6 Scanning electron microscopy images $(\times 3,000)$ of slot floor surface in non-coated and DLC-coated brackets before and after static friction test.

(a) Non-coated bracket before static friction test, (b) non-coated bracket after static friction test, (c) DLC-coated bracket before static friction test, and (d) DLC-coated bracket after static friction test.

was higher for all bracket and wire combinations in the presence of artificial saliva (wet conditions) than under dry conditions. The present study also showed that the static friction between wires and non-coated brackets under wet conditions was significantly higher for most wire and angulation combinations. However, there was almost no difference in static friction under wet and dry conditions for the DLC-coated brackets. This indicates that the DLC coating effectively reduced static friction under both dry and wet conditions.

Although the precise reason why DLC coating did not increase the static friction under wet condition is not yet clear, it is possibly related to the influence of the surface wettability on the static friction. The DLC coating may have made the surface more hydrophobic, thus reducing its wettability. In such a situation, the PBS may have difficulty entering the small gap between the bracket and the wire. In contrast, for the non-coated bracket, the PBS can easily enter the gap because of the hydrophilic nature of the bracket surface. This would lead to an increase in static friction because of the viscosity of the PBS. Further investigation is required in order to clarify the relationship between the surface wettability and friction.

It is well known that in addition to electrolyte and water, saliva contains macromolecules such as proteins and glycoproteins. Kusy et al. ${ }^{31)}$ reported that the viscosity of saliva did not affect the friction between a bracket and wire under wet conditions. Therefore, we employed a PBS solution in the present study. Leal et $a l .{ }^{32}$ reported that higher friction forces were found when distilled water was used. The influence of the presence of macromolecules on the friction between orthodontic wire and DLC-coated brackets should be further investigated.

The DLC-coated bracket reduced the rate at which increases occurred in static friction in the combination of wires and several angulations under both dry and wet conditions. The DLC-coated bracket also reduced static friction in heavy wires, irrespective of the wire material, thereby enabling teeth to move with heavy wires, which is very advantageous for effective tooth movement in sliding mechanics and shortens the orthodontic treatment period ${ }^{33,34)}$.

No marked difference was observed in the appearance of the slot surface for DLC-coated bracket following the static friction test. No peeling or cracking of the DLC coating was found, indicating that it was firmly attached to the slot surface and was very stable.

In the present study, the static friction test was performed only once for each bracket in order to avoid frictional damage. In orthodontic treatments, brackets 
are typically placed in the oral cavity for approximately 2 years, and activities such as eating food or teeth brushing may influence the static friction between the bracket and the wire. Further studies are required to determine the long-term durability of DLC coatings under clinical conditions.

\section{CONCLUSIONS}

The DLC coating was homogeneously deposited on the whole slot surface of the bracket by the PECVD. The DLC-coated bracket markedly reduced static friction between the bracket and wire, irrespective of the conditions (dry or wet), wire materials (SS or Ti-Mo), wire sizes $(0.019 \times 0.025$ or $0.021 \times 0.025$ inches $)$, and angulations $\left(0^{\circ}, 1^{\circ}, 3^{\circ}, 5^{\circ}\right.$ and $\left.10^{\circ}\right)$ used.

\section{REFERENCES}

1) Kapila S, Angolkar PV, Duncanson MG Jr, Nanda RS. Evaluation of friction between edgewise stainless steel brackets and orthodontic wires of four alloys. Am J Orthod Dentofacial Orthop 1990; 98: 117-126.

2) Liu X, Ding P, Lin J. Effects of bracket design on critical contact angle. Angle Orthod 2013; 83: 877-884.

3) Drescher D, Bourauel C, Schumacher HA. Frictional forces between bracket and arch wire. Am J Orthod Dentofacial Orthop 1989; 96: 397-404.

4) Redlich M, Mayer Y, Harari D, Lewinstein I. In vitro study of frictional forces during sliding mechanics of "reduced-friction" brackets. Am J Orthod Dentofacial Orthop 2003; 124: 69-73.

5) Andreasen GF, Quevedo FR. Evaluation of friction forces in the $0.022 \times 0.028$ edgewise bracket in vitro. J Biomech 1970; 3 : 151-160.

6) Thorstenson GA, Kusy RP. Comparison of resistance to sliding between different self-ligating brackets with secondorder angulation in the dry and saliva states. Am J Orthod Dentofacial Orthop 2002; 121: 472-482.

7) Kusy RP. Ongoing innovations in biomechanics and materials for the new millennium. Angle Orthod $2000 ; 70$ : 366-376.

8) Kusy RP, Whitley JQ. Influence of archwire and bracket dimensions on sliding mechanics: derivations and determinations of the critical contact angles for binding. Eur J Orthod 1999; 21: 199-208.

9) Articolo LC, Kusy RP. Influence of angulation on the resistance to sliding in fixed appliances. Am J Orthod Dentofacial Orthop 1999; 115: 39-51.

10) Kusy RP, Tobin EJ, Whitley JQ, Sioshansi P. Frictional coefficients of ion-implanted alumina against ion-implanted beta-titanium in the low load, low velocity, single pass regime. Dent Mater 1992; 8: 167-172.

11) Farronato G, Maijer R, Carìa MP, Esposito L, Alberzoni D, Cacciatore G. The effect of Teflon coating on the resistance to sliding of orthodontic archwires. Eur J Orthod 2012; 34: 410417.

12) Husmann $P$, Bourauel C, Wessinger M, Jäger A. The frictional behavior of coated guiding archwires. J Orofac Orthop 2002; 63: 199-211.

13) Kao CT, Guo JU, Huang TH. Comparison of friction force between corroded and noncorroded titanium nitride plating of metal brackets. Am J Orthod Dentofacial Orthop 2011; 139: 594-600.

14) Muguruma T, Iijima M, Brantley WA, Mizoguchi I. Effects of a diamond-like carbon coating on the frictional properties of orthodontic wires. Angle Orthod 2011; 81: 141-148.
15) Muguruma T, Iijima M, Brantley WA, Nakagaki S, Endo K, Mizoguchi I. Frictional and mechanical properties of diamondlike carbon-coated orthodontic brackets. Eur J Orthod 2013; 35: 216-222.

16) Cha JY, Kim KS, Hwang CJ. Friction of conventional and silica-insert ceramic brackets in various bracket-wire combinations. Angle Orthod 2007; 77: 100-107.

17) Stefanos S, Secchi AG, Coby G, Tanna N, Mante FK. Friction between various self-ligating brackets and archwire couples during sliding mechanics. Am J Orthod Dentofacial Orthop 2010; 138: 463-467.

18) Del Prado G, Terriza A, Ortiz-Pérez A, Molina-Manso D, Mahillo I, Yubero F, Puértolas JA, Manrubia-Cobo M, Gómez Barrena E, Esteban J. DLC coatings for UHMWPE: relationship between bacterial adherence and surface properties. J Biomed Mater Res A 2012; 100: 2813-2820.

19) Ohgoe $Y$, Kobayashi S, Ozeki K, Aoki H, Nakamori H, Hirakuri KK, Miyashita O. Reduction effect of nickel ion release on a diamond-like carbon film coated onto an orthodontic archwire. Thin Solid Films 2006; 497: 218-222.

20) Kobayashi S, Ohgoe Y, Ozeki K, Hirakuri K, Aoki H. Dissolution effect and cytotoxicity of diamond-like carbon coatings on orthodontic archwires. J Mater Sci Mater Med 2007; 18: 2263-2268.

21) Ireland AJ, Sherriff M, McDonald F. Effect of bracket and wire composition on frictional forces. Eur J Orthod 1991; 13: 322-328.

22) Stannard JG, Gau JM, Hanna MA. Comparative friction of orthodontic wires under dry and wet conditions. Am J Orthod 1986; 89: 485-491.

23) Wada N, Gaczi PJ, Solin SA. "Diamond-like" 3-fold coordinated amorphous carbon. J Non-Cryst Solids 1980; 35-36: 543-548.

24) Ferrari AC, Robertson J. Interpretation of Raman spectra of disordered and amorphous carbon. Phys Rev B 2000; 61: 14095-14107.

25) Wichelhaus A, Geserick M, Hibst R, Sander FG. The effect of surface treatment and clinical use on friction in NiTi orthodontic wires. Dent Mater 2005; 21: 938-945.

26) Garner LD, Allai WW, Moore BK. A comparison of frictional forces during simulated canine retraction of a continuous edgewise arch wire. Am J Orthod Dentofacial Orthop 1986; 90: 199-203.

27) Bourauel C, Fries T, Drescher D, Plietsch R. Surface roughness of orthodontic wires via atomic force microscopy, laser specular reflectance, and profilometry. Eur J Orthod 1998; 20: 79-92.

28) Kusy RP, Whitley JQ, Mayhew MJ, Buckthal JE. Surface roughness of orthodontic archwires via laser spectroscopy. Angle Orthod 1988; 58: 33-45.

29) Saunders CR, Kusy RP. Surface topography and frictional characteristics of ceramic brackets. Am J Orthod Dentofacial Orthop 1994; 106: 76-87.

30) Downing A, McCabe JF, Gordon PH. The effect of artificial saliva on the frictional forces between orthodontic brackets and archwires. Br J Orthod 1995; 22: 41-46.

31) Kusy RP, Schafer DL. Effect of salivary viscosity on frictional coefficients of orthodontic archwire/bracket couples. J Mater Sci Mater Med 1995; 6: 390-395.

32) Leal RC, Amaral FL, França FM, Basting RT, Turssi CP. Role of lubricants on friction between self-ligating brackets and archwires. Angle Orthod 2014; 84: 1049-1053.

33) McLaughlin RP, Bennett JC. The transition from standard edgewise to preadjusted appliance systems. J Clin Orthod 1989; 23: 142-153.

34) Ouchi K, Watanabe K, Koga M, Isshiki Y, Kawada E, Oda Y. The effects of retraction forces applied to the anterior segment of orthodontic arch wires: differences in wire deflection with wire size. Bull Tokyo Dent Coll 1998; 39: 183-188. 